\title{
O PERCURSO À DOCÊNCIA UNIVERSITÁRIA REFLEXIVA: O FASCÍNIO, AS INCERTEZAS E O PRAZER DE SE DESCOBRIR UM DOCENTE “ENSINANTE”.
}

\author{
Carmen Lúcia Dias, Amanda Delibório, Ana Teresa S. Maia de Araújo, Natalie Perez Mendes \\ Universidade do Oeste Paulista - UNOESTE, Mestrado em Educação, Presidente Prudente, SP. E-mail: \\ kkaludias@gmail.com
}

\section{RESUMO}

A partir da contribuição de autores renomados, este artigo tem por objetivo realizar uma retrospectiva pelas concepções de educação, de escola e da docência universitária ao longo do tempo, abordando a longa trajetória percorrida desde a docência medieval quase que "doméstica", até chegarmos no século XXI com uma perspectiva de uma docência voltada para a recuperação do ser humano na sua totalidade, dentro do paradigma da formação reflexiva do estudante, numa vertente que considera não só "o fascínio" desse tipo de docência como também "a transpiração" decorrente do trabalho a ser dispendido para que ela deixe de ser uma teoria encantadora para se concretizar em uma realidade prática. Portanto, que permita ao docente (re)descobrir "o prazer" de ensinar pela adoção de uma postura de "ensinante", onde "a incerteza" e "a dúvida" possam ser aliadas do saber.

Palavras- chave: Educação Reflexiva, Formação de Professores, Prazer de Ensinar.

\section{THE ROUTE TO UNIVERSITY TEACHING REFLECTIVE: THE FASCINATION, THE UNCERTAINTIES AND THE PLEASURE OF DISCOVERING A TEACHER "TEACHING BEING".}

\begin{abstract}
From the contribution of renowned authors, this article aims to perform a retrospectively by the concepts of education, school and university teaching over time, addressing the long road taken from the medieval teaching almost "home" until we reach the twenty-first century with a prospect of teaching toward the recovery of the human being in its entirety, within the paradigm of reflexive education student, in a trend that considers not only "the fascination" of this type of teaching as well as "sweating during the work to be spent so that it's to be a lovely theory to be realized in a practical reality, allowing the teacher (re) discover the "pleasure" of teaching by adopting an attitude of "teaching being" where "uncertainty" and "doubt" can be combined of knowledge
\end{abstract}

Keywords: Reflective Education, Teacher's Education, Teaching of Pleasure. 
INTRODUÇÃO

Quando pensamos nos objetivos da educação, observamos que ainda que em formatos diferentes, os conceitos nucleares das respostas obtidas invariavelmente versam sobre a sua contribuição para a formação individual e coletiva do ser humano, dada a sua característica de formar pessoas para lidar com a vida cotidiana em sociedade.

Transitando nesse paradigma, o relatório da UNESCO, em sua edição 1996 (UNESCO, 1998) coloca como um dos principais papéis da educação o de dotar o ser humano da capacidade de tomar o seu destino nas mãos e contribuir para o progresso social através de uma participação responsável.

Cumpre lembrar, que o caminho para o alcance desse objetivo inovador de se trabalhar o conhecimento para a formação para a totalidade, encontra na fragmentação do processo de ensino, hegemônica na sua historicidade, um enorme desafio a ser superado.

Nessa vertente, pretende-se com esse artigo realizar uma revisitação pelas concepções de educação, de escola e da docência universitária ao longo do tempo até alcançar o "fascinante" paradigma da formação reflexiva do estudante, valorizando "o trabalho", "a transpiração" necessária para que ela deixe de ser uma teoria encantadora para se constituir em uma realidade prática, que permita ao docente (re)descobrir "o prazer" de ensinar.

\section{A EDUCAÇÃO}

Lançando nossos olhares para as formas como a educação tem ocorrido ao longo da história da humanidade podemos vislumbrar como as concepções de educação responderam mais à interesses políticos, religiosos e militares dominantes numa dada época do que ao ideário da educação em si.

Na Idade Média (476-1473) o ensino acontecia com a intencionalidade de formar a pessoa para a vida, havendo preponderância dos valores culturais, em relação à necessidade de se aprender um ofício (ENGUITA, 1989).

Essa educação medieval era pautada pelo intelectualismo, verbalismo e dogmatismo, sendo baseada no método intuitivo, na memorização e repetição mecânica do que era transmitido pelo professor (LIBÂNEO, 1994).

A partir do século XII o ensino superior emergiu dentro de uma filosofia de ensino tradicional, corporativista, com os saberes dispostos em livros, cujos conteúdos eram tidos como verdades absolutas, dirigida muito mais para o domínio do poder dos discursos formais, do que para a aquisição de saber crítico ou para a inovação (MONROE,1979). 
Na Idade Moderna (1453-1789) essa realidade começou a se modificar a partir do avanço da Revolução Industrial, havendo uma incorporação da lógica capitalista de mercado na educação pela necessidade de se conseguir mão-de-obra dentro dos padrões exigidos pelas indústrias em expansão.

Nesse período ganhou corpo o ensino baseado na Pedagogia Tradicional, centrado no professor, que através da aula expositiva, verbalizava o seu conhecimento exprimido em uma grande quantidade e variedade de informações e conceitos isolados, desvinculados da realidade, que tinham que ser memorizados pelos alunos (atitude passiva), sem considerar suas diferenças individuais (MIZUKAMI,1986; LIBÂNEO, 1994).

Na Idade Contemporânea (1789 até os dias atuais), principalmente a partir do século XX, esse tradicionalismo abriu espaço para a Pedagogia Renovada que advoga em prol do verdadeiro sentido da educação e deste movimento surgiu a corrente da Pedagogia Progressista, encabeçada por Dewey (1859-1952) que inovou ao propor uma aprendizagem baseada em problemas que valorizem experiências concretas, motivadoras para o estímulo cognitivo visando escolhas e soluções criativas (LIBÂNEO, 1994 ; CYRINO; TORALLES-PEREIRA, 2004).

Essa pedagogia problematizadora da vida "vivida", encontra solo fértil nas ideias de Morin (2013) que defende um saber mais global, capaz de responder a inadequação crescente existente entre os saberes compartimentados entre disciplinas, e, realidades cada vez mais polidisciplinares, cujas soluções só podem ser pensadas em seus contextos.

Efetivamente, a inteligência que só sabe separar fragmenta o complexo do mundo em pedaços separados, fraciona os problemas, unidimensionaliza o multidimensional. Atrofia as possibilidades de compreensão e de reflexão, eliminando assim as oportunidades de um julgamento corretivo ou de uma visão a longo prazo. (MORIN, 2003, p.14).

Adotando essa linha de raciocínio, a educação universitária contemporânea pressupõe um ensino centrado no aluno, cabendo ao docente o papel de auxiliá-lo a descobrir significados, a buscar informações, a rever experiências e a adquirir habilidades (MASSETO, 2003). Em essência, busca-se despertar a "veia de aprendiz" no estudante, ensinando-o a adquirir o que o Balzan (2000) chama de "autonomia de voo" .

\section{A ESCOLA}

Quando abordamos a temática da educação temos que considerar o cenário "vivo" onde ela ocorre de forma institucionalizada: a escola. 
Enguita (1989) coloca que até a Idade Média (476 - 1453) a formação humana não era institucionalizada. Ela acontecia no dia a dia no seio da própria família ou através do intercâmbio familiar, pois se considerava que o afeto podia interferir no aprendizado, havendo um contrato de aprendizagem para dar estabilidade a essa relação, onde estava implícito o princípio da reciprocidade no trato dos aprendizes pelas famílias intercambiárias.

No limiar do século XII, em plena "Idade das Trevas", foram constituídas as primeiras Universidades, sendo restritas a poucos campos do saber como a Teologia (Universidade de Paris), o Direito (Universidade de Bolonha) e a Medicina (Universidade de Montpellier) (TRINDADE, 1999).

Na Idade Moderna (1453 a 1789), com a ascensão da burguesia (século XVIII) surge o fenômeno da escolarização com a criação dos colégios de labor com jornadas extenuantes e desumanas para internamento e adestramento de crianças, órfãos, desocupados e etc. visando formar mão de obra barata e disciplinar caráter e os colégios religiosos que tinham como função ensinar o respeito à ordem social e à resignação diante das injustiças sociais (ENGUITA, 1989).

A institucionalização da ciência no ensino superior se inicia no seio da Universidade Renascentista, ancorada no capitalismo, no humanismo literário e artístico, sobretudo nas repúblicas urbanas italianas (Universidades de Florença e Roma) e a partir daí se expandem para os principais centros europeus (TRINDADE, 1999).

Na Idade Contemporânea (1789 até os dias atuais) as escolas aparecem mais voltadas à formação profissional para atender as demandas de uma sociedade capitalista, industrializada e urbanizada. Eram espaços muito semelhantes aos conventos e quartéis, tal a obsessão pela organização, pela ordem, pela pontualidade, pela compostura e pela disciplina de corpo e movimento, o que acabou por influenciar na rígida arquitetura espacial da sala de aula que perdura até os dias atuais (ENGUITA, 1989).

A partir do século XIX, a ciência e a pesquisa se consolidaram na Universidade, sob forte impulso do iluminismo, do enciclopedismo e dos efeitos radicais da Revolução Francesa de 1789.

O Modelo adotado por essas Universidades de início, era o Napoleônico (Francês), marcado pela maior dependência em relação ao Estado/Imperador e posteriormente o Modelo Humboldtiano (Alemão), com mais autonomia na sua administração e na ciência produzida (TRINDADE,1999).

Pimentel (1994) considera que essas práticas universitárias contemporâneas convergem para um perfil educacional, onde a educação se aproxima do mundo do trabalho, sem contudo 
deixar de contribuir para a construção da personalidade do estudante, atribuindo sentido ao seu papel de homem cidadão.

\section{O DOCENTE}

$\mathrm{Na}$ atualidade, diante das indagações e questionamentos da população quanto à qualidade da educação institucionalizada desde os níveis mais básicos até a universitária, temos também que refletir sobre o universo de atuação de um de seus principais atores: o professor.

Como podemos repensar a atuação docente almejando uma concepção de uma prática reflexiva? Como tem sido o ensino oferecido aos estudantes universitários e em que medida as práticas pedagógicas dos docentes do Ensino Superior tem contribuído para a formação de bons profissionais na área? Quais pressupostos teóricos e pedagógicos têm sustentado suas práticas? Elas superam o ensino tradicional dos conteúdos?

Historicamente, embora haja registros de estabelecimento de ensino destinado à formação docente já a partir do século XVII, não havia até então, uma preocupação maior com a formação do docente que deveria em geral, "aprender fazendo". Somente no século XIX com a necessidade da instrução popular que conduziu à organização dos sistemas nacionais de ensino, foram criadas na França, as Escolas Normais de formação de professores que se disseminaram pelo mundo (SAVIANI, 2009).

Nelas, a formação de docentes para atuarem nos níveis primário e secundário se efetivou tendo por base a Pedagogia Tradicional, baseada na transmissão oral das grandes verdades acumuladas pela humanidade, que por repetição de atividades e exercícios deveriam ser decoradas e depois reproduzidas (LIBÂNEO, 1994).

E até hoje, na plenitude do século XXI, grande parte do sistema de ensino mundial segue essa lógica tradicional, inclusive nas Universidades, onde segundo Masetto (2003), o ensino se dá por um currículo fechado, com disciplinas conteudísticas, tecnicistas, com pouca abertura para outras áreas do conhecimento e interdisciplinaridade, que são transmitidos por aulas expositivas e avaliados por meio de provas e outros métodos tradicionais.

Essa realidade pouco transformadora é agravada pelo fato dos docentes universitários, em sua maioria serem requisitados principalmente pelo saber técnico de uma profissão, tendo pouco domínio sobre os pressupostos teóricos que apoiam os processos de ensino e de aprendizagem.

[...] todos os professores têm um domínio do conhecimento amplo, profundo e atualizado, não só do conhecimento programático como da ciência que ensinam. Têm também o conhecimento das ciências correlatas. Nem todos, 
porém, têm o conhecimento da produção do conhecimento e poucos têm o conhecimento claro e consciente do que é ensinar. (PIMENTEL,1994, p. 85).

Daí, talvez decorra a constatação feita por Schön $(2000$, p.19) quando afirma que "o que os aspirantes a profissionais mais precisam aprender, as escolas profissionais parecem menos capazes de ensinar".

Para Tardif (2002), o professor ideal deve possuir além do saber técnico e curricular, conhecimentos relativos às ciências da educação e à pedagogia e desenvolver um saber prático baseado em sua experiência cotidiana com os alunos, que os instigue a pensar através de metodologias ativas.

Freire (2011) é outro autor que advoga em favor dessa educação para a autonomia que exige participação ativa dos sujeitos envolvidos no processo de ensino e de aprendizagem.

[...] quem forma se forma e re-forma ao formar e quem é formado forma-se e forma ao ser formado. É nesse sentido que ensinar não é transferir conhecimentos, conteúdos, nem formar é ação pela qual um sujeito criador dá forma, estilo ou alma a um corpo indeciso e acomodado. Não há docência sem discência, as duas se explicam e seus sujeitos, apesar das diferenças que os conotam, não se reduzem à condição de objeto um do outro. Quem ensina aprende ao ensinar e quem aprende ensina ao aprender. (FREIRE, 2011, p. 25).

Para Libâneo (2006), se queremos um aluno reflexivo, precisamos também de um professor crítico reflexivo.

Porém, a docência reflexiva requer trabalho do professor, num processo que Almeida (2008) denomina de autoformatação, que exige a desconstrução de uma forma de ensinar e aprender do professor (formado na lógica da disciplinaridade e especialidade) para reconstruí-la em novas bases, onde haja um esforço para aprender a religar parte e todo, fenômeno e ambiente, vida e ideias.

\section{CONSIDERAÇÕES FINAIS}

Em pleno século XXI diante de uma perspectiva de uma docência voltada para a recuperação do ser humano na sua totalidade é preciso sem deixar de considerar tudo aquilo que já foi produzido na trajetória do conhecimento, buscar novos sentidos na tríade ensino-escoladocência.

Adotando essa linha de raciocínio, a educação universitária contemporânea terá que buscar um caminho onde o estudante deixe de ser objeto do conhecimento já estabelecido para 
se transformar em sujeito do aprendizado, num processo que valoriza a atitude e a criatividade. Eis aqui o encantamento, "o fascínio" da busca da formação reflexiva do estudante, é o ser humano pensado na sua totalidade, assumindo o papel de protagonista de sua história.

Esse ensino transformador, por sua vez exige que as escolas deixem de ser o "espaço árido", desinteressante e burocrático no qual se transformaram para assumirem uma nova disposição espacial que permita "o encontro entre pessoas", com formação de pequenos grupos de aprendizagem, que se constituirão em espaços "férteis" de convivência entre docentes e alunos, com inserção precoce em cenários práticos de aprendizagem.

E se alterar a arquitetura escolar gera "transpiração", mais trabalhoso ainda será transformar as práticas docentes, uma vez que a busca da docência reflexiva exige que o professor se descontrua para se reconstruir em outras bases, abandonando o papel de detentor do saber para se colocar como alguém capaz de transformar a informação do aluno em sabedoria.

Nessa vertente, despido da obrigação de ser o detentor do saber, há espaço para que ele não se desconcerte diante da "incerteza e da dúvida", para que se descubra um docente ensinante, que se mostre conhecendo e não conhecedor, que se mostre pensante e não dono do pensamento (FERNÁNDEZ, 2001).

Eis o caminho, ao abrir-se para o aprendizado ao mesmo tempo em que ensina, o docente pode (re)descobrir "o prazer de ensinar".

\section{REFERÊNCIAS}

ALMEIDA, M. C. X. Educação como aprendizagem da vida. Educar em Revista, n. 32. Curitiba, 2008. 9 p.

BALZAN, N.C. Indissociabilidade ensino-pesquisa como princípio metodológico. In: VEIGA, I.P.A. e CASTANHO, M.E. Pedagogia Universitária: a aula em foco. Campinas: Papirus, 2000 parte I - cap. 5.

CYRINO, E.G., TORALLES-PEREIRA, M.L. Trabalhando com estratégias de ensino-aprendizado por descoberta na área da saúde: a problematização e a aprendizagem baseada em problemas.

Cadernos de Saúde Pública, Rio de Janeiro, (20)3:780-788, mai-jun, 2004.

ENGUITA, M. A Face oculta da escola. Porto Alegre: Artes Médicas. 1989.

FERNÁNDEZ, A. O saber em jogo: a psicoterapia propiciando autorias de pensamento. Porto Alegre: Artmed, 2001.

FREIRE, P. Pedagogia da autonomia: saberes necessários à prática educativa; 43. ed. São Paulo: Paz e Terra, 2011. 
LIBÂNEO, J. C. Didática. 2. ed. São Paulo, Cortez, 1994.

- Reflexividade e formação de professores: outra oscilação do pensamento pedagógico brasileiro? In: PIMENTA, S. G.; GHEDIN, E. (Orgs.). Professor reflexivo no Brasil: gênese e crítica de um conceito. 4. ed. São Paulo: Cortez, 2006. p. 53-79.

MASETTO, M. T. Competência pedagógica do professor universitário. São Paulo: Summus, 2003.

MIZUKAMI, M. G. N. Ensino: as abordagens do processo. São Paulo: EPU, 1986.

MONROE. P. História da Educação. São Paulo: Ed. Nacional, 1979.

MORIN, E. A cabeça bem-feita: repensar a reforma, reformar o pensamento; tradução Eloá Jacobina. - 8. ed. Rio de Janeiro: Bertrand Brasil, 2003.

PIMENTEL, M.G. O professor em construção. 2. ed. Campinas: Papirus, 1994. 95p.

SAVIANI, D. Formação de Professores: aspectos históricos e teóricos do problema no contexto brasileiro. Rev. Brasileira de Educação, v.14 n.40 jan/abr. 2009.

SCHÖN, D.A. Educando o profissional reflexivo: um novo design para o ensino e a aprendizado. Porto Alegre: Artes Médicas Sul, 2000. p.15-19.

TARDIF, M. Saberes docentes e formação profissional. Petrópolis: Vozes, 2002.

TRINDADE, H. Universidade em perspectiva: sociedade, conhecimento e poder. Rev. Brasileira de Educação, n.10 jan/fev,/mar./abr. 1999.

UNESCO /Edições ASA for the first Portuguese edition 1996 São Paulo: Cortez, 1998. 